\title{
Missed presentation of Crohn's disease in a patient with a fistulating thigh abscess: a case report
}

\author{
Deborah Ferguson", Aravind Suppiah, Eleanor Richards, Jeremy Wilson, Deepak Pai, Asit Kar
}

\begin{abstract}
Background: Musculoskeletal presentations of Crohn's disease are rare and they include psoas abscess, thigh abscesses and in extreme cases septic arthropathy.

Case presentation: Herein, we present a 53 year old gentleman with bilateral thigh fistulae discovered to be a new diagnoses of extra-intestinal Crohn's disease

Conclusion: It is important to consider Crohn's disease in patients that present with unusual or persistent fistulae and to consider this essential when there are atypical organisms present.
\end{abstract}

\section{Background}

Crohn's disease $(\mathrm{CD})$ is a granulomatous inflammatory condition affecting the gastrointestinal tract with an incidence of 1-3 per 100,000 [1]. It usually presents with gastrointestinal or non-specific symptoms such as weight loss. CD is associated with an array of extraintestinal manifestations include eyes (uveitis, iritis), skin (erythema nodusum, pyoderma ganrenosum), cardiorespiratory (interstitial lung disease, pericarditis) and prolithogenic conditions (chole- or nephrolithiasis). Musculoskeletal involvement is less common and typically involves sero-negative non-deforming polyarthropathy or ankylosing spondylitis.

A hallmark of $C D$ is fistula formation which occurs in $17-50 \%$ of patients, usually between bowel, abdominal viscera or to abdominal wall or perineum [2]. Fistulation into soft tissue or peri-articular regions are unusual. Psoas abscesses are rare but a documented presentation of CD [3]. Musculoskeletal fistulas are extremely rare with only 3 reported cases to our knowledge of hamstring [4] and gluteal abscesses [5]. Additionally, none of these cases report these as first presentations of CD, but rather complications in patients with already known disease.

\footnotetext{
* Correspondence: deborahferguson@doctors.org.uk
Scunthorpe General Hospital, Cliff Gardens Cliff Gardens, Scunthorpe, South

* Correspondence: deborahferguson@doctors.org.uk
Scunthorpe General Hospital, Cliff Gardens Cliff Gardens, Scunthorpe, South Humberside DN15 7BH, UK
}

(c) 2010 Ferguson et al; licensee BioMed Central Ltd. This is an Open Access article distributed under the terms of the Creative Commons Attribution License (http://creativecommons.org/licenses/by/2.0), which permits unrestricted use, distribution, and reproduction in any medium, provided the original work is properly cited.
We present a unique case of patient with previously unknown $\mathrm{CD}$, presenting for the first time with a discharging right hip abscess in the absence of gastrointestinal symptoms. We discuss the subsequent diagnostic pitfalls leading to delayed diagnosis, and put identify warning features that should alert any surgeon as to this unique presentation of $\mathrm{CD}$, and also $\mathrm{CD}$ as possible aetiology in musculo-skeletal pathology [6].

\section{Case presentation}

A 53-year-old white British gentleman presented with a 2 month history of purulent discharge from a sinus on the right lateral thigh. He was otherwise systemically well and has no significant past medical history. On admission he was apyrexial and haemodynamically stable. Examination revealed normal right hip movement. X-ray showed soft tissue radiolucent abnormality just distal to the lesser trochanter. Inflammatory markers were raised (CRP 165, WCC $13.1 \times 10^{9} / \mathrm{L}$ and neutrophils $\left.10.5 \times 10^{9} / \mathrm{L}\right)$ and wound cultures grew group B Streptococci and he was commenced on flucloxacillin and benzyl penicillin. Limited-view right hip MRI showed two locules of gas in the soft tissue just outside piriformis muscle and adjacent to the right femur (Figure 1) and signal changes in the right gluteal muscles (Figure 2) and a small collection within the muscles lateral to the right hip joint with no evidence of osteomyelitis. 


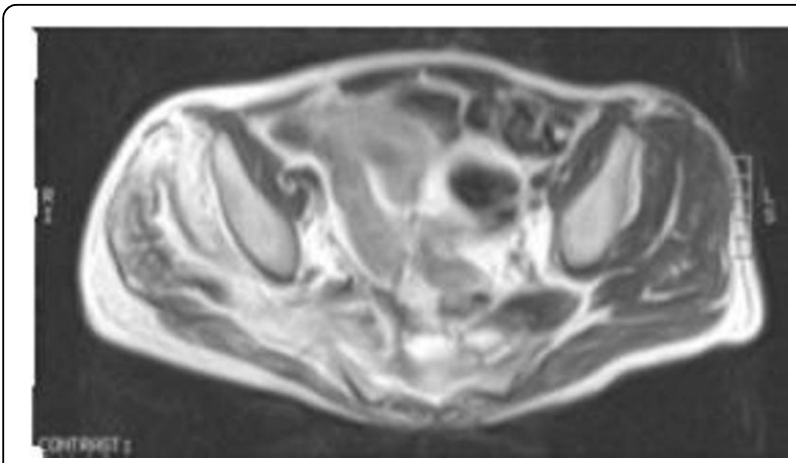

Figure $1 \mathrm{CT}$ showing gas in the bladder and two locules of gas in the soft tissue just outside piriformis muscle and adjacent to the right femur.

He was referred to orthopaedics where right hip abscess exploration with washout and primary closure was performed and the patient discharged the following day. He re-presented a week later with recurrent discharge from the same site, which was re-explored but on this occasion left open. He underwent further washout with closure 3 days later. The discharging "sinus" recurred again within 4 days. On this occasion, the wound was left open and left to heal by secondary intention. Plastics opinion was sought due to complex nature of the lesion and already extensive management. This complicated thigh wound was managed with interval washouts and long-term antibiotics.

Five years later, the patient was referred to general surgical clinic with presumed left leg cellulitis. He still had a chronic right-sided discharging sinus. Abdominal $\mathrm{CT}$ revealed a vesico-ileal fistula with thickened bowel

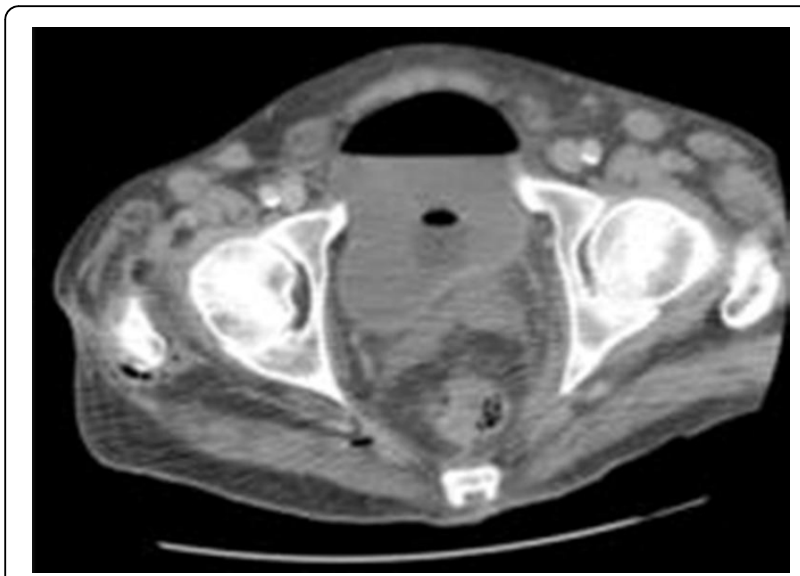

Figure 2 STIR axial of the pelvis showing oedema with in the soft tissue involving the right piriformis muscle extending into the gluteal muscles on right side.

wall and gas pockets in the left poster-medial thigh and the right proximal femoral and para-sacral spaces, suggestive of fistulating $\mathrm{CD}$. The following day, right hemicolectomy, excision of ileo-vesical fistula and drainage of left thigh abscess was performed. Post-operative histology confirmed CD. The patient was discharged after 24 days requiring no treatment for $\mathrm{CD}$ on discharge and was follow-up by gastroenterologist. To date the patient remains well with no evidence of further soft tissue injury.

\section{Discussion}

Psoas abscess is a rare but recognised complication of CD. Thigh sinuses and periarticular collections are extremely rare and to our knowledge there are only 3 reported cases of thigh disease and 2 reports of $C D$ leading to septic arthritis, one of whom died. In both cases, the patient was already known to have CD [6]. This is the first case of undiagnosed CD presenting as initially bilateral thigh abscesses which caused diagnostic and hence, subsequent therapeutic dilemma lasting several years.

Diagnosis was delayed due to the absence of colorectal symptoms and the inability to visualise a communicating entero-cutaneous fistula on limited view right hip MRI. The patient then presented with a further contra lateral cellulitis, suggesting underlying infection from which enterococcus species was grown. Urgent surgical referral was sought and the patients went on to have curative surgery and remains symptom free at 1 year.

\section{Conclusion}

In the absence of a clear source or septic focus for hip abscess or septic arthritis of the hip, early gastroenterology opinion must be sought, even in the absence of colorectal symptoms, to avoid delays in diagnosis and treatment. This becomes more urgent in the presence of later warning signs which are; recurrence of peri-articular collections despite washouts, the development of a contra-lateral collection or presence of atypical organisms.

\section{Consent}

Written informed consent was obtained from the patient for publication of this case report and accompanying images. A copy of the written consent is available for review by the Editor-in-Chief of this journal.

\section{Authors' contributions}

DF reviewed the patients case notes, drafted the initial and final copy of the case report and completed submission after reading and approving final manuscript. AS reviewed the patients case notes and was a major contributor in writing and then reading and approving final manuscript. He also gained patient consent. ER reviewed the manuscript, reviewed, submitted the radiological imaging and read and approved the final manuscript. JW read and approved the final manuscript. DP reviewed and 
assisted with submission of the radiological imaging alongside reading and approving final manuscript. AK reviewed the patients case notes and reviewed and read and approved the final manuscript.

\section{Competing interests}

The authors declare that they have no competing interests.

Received: 30 November 2009

Accepted: 14 January 2010 Published: 14 January 2010

\section{References}

1. Crohns disease. http://www.emedicinehealth.com/crohn_disease/ article_em.htm.

2. Shreeve DR, Ormerod LP, Dunbar EM: Crohn's disease with fistulae involving joints. J R Soc Med 1982, 75(12):946-948.

3. Lobo DN, Dunn WK, Iftikhar SY, Scholefield JH: Psoas abscesses complicating colonic disease: imaging and therapy. Ann R Coll Surg Engl 1998, 80(6):405-409.

4. Denton ER, Jamieson CP, Rankin SC: Case report: abscess of the adductor muscles of the thigh-an unusual complication of Crohn's disease. $\mathrm{Br} J$ Radiol 1996, 69(825):865-866.

5. Mayer DA, Zingale RG, Tsapogas MJ: Case study: gluteal abscess due to Crohn's disease. Ostomy Wound Manage 1993, 39(5):30-34.

6. Peravali R, Purohit N, Dutta $\mathrm{S}$, Mohsen $\mathrm{Y}$ : Septic arthritis of the hip: a rare complication of fistulizing Crohn's disease. Colorectal Dis 2009, 11(3):323-324.

doi:10.1186/1757-1626-3-26

Cite this article as: Ferguson et al: Missed presentation of Crohn's

disease in a patient with a fistulating thigh abscess: a case report. Cases Journal 2010 3:26.

Publish with Biomed Central and every scientist can read your work free of charge

"BioMed Central will be the most significant development for disseminating the results of biomedical research in our lifetime. "

Sir Paul Nurse, Cancer Research UK

Your research papers will be:

- available free of charge to the entire biomedical community

- peer reviewed and published immediately upon acceptance

- cited in PubMed and archived on PubMed Central

- yours - you keep the copyright 